\title{
Thermal Imaging as a Non Destructive Testing Implemented in Heritage Conservation
}

\author{
Rodrigo Velázquez Castillo ${ }^{1}$, Miguel A. Pérez-Lara ${ }^{1}$, Eric Rivera-Muñoz ${ }^{2}$, José L. Arjona ${ }^{3}$, Mario E. \\ Rodríguez-García ${ }^{2}$, Andrés Acosta-Osorio ${ }^{1} \&$ Miguel Galván-Ruiz ${ }^{1}$ \\ ${ }^{1}$ División de Investigación y Posgrado, Facultad de Ingeniería, Universidad Autónoma de Querétaro. CU Cerro \\ de las Campanas, Querétaro, México \\ ${ }^{2}$ Centro de Física Aplicada y Tecnología Avanzada, Departamento de Nanotecnología, Universidad Nacional \\ Autónoma de México Campus Juriquilla, Querétaro, México \\ ${ }^{3}$ FES Cuautitlán, Universidad Nacional Autónoma de México, Cuautitlán Izcalli, Estado de México, México \\ Correspondence: Miguel Galván-Ruiz, Facultad de Ingeniería-Universidad Autónoma de Querétaro, CU Cerro \\ de las Campanas S/N 76010, Querétaro, México. E-mail: mgr@uaq.edu.mx
}

\author{
Received: September 12, 2012 Accepted: September 25, 2012 Online Published: October 9, 2012 \\ doi:10.5539/jgg.v4n4p102 \\ URL: http://dx.doi.org/10.5539/jgg.v4n4p102
}

\begin{abstract}
The aim of this work is analyzethe relevance of Non Destructive Technique (NDT) thermal infrared imaging (TIRI) as a way of reference to the heritage conservation. The assessment of thermography testing was done in order to evaluate the correspondence concerning the physical and chemical characterization and compatibility among original and restored plastered mortars and stuccos, considering the correlation betweenthermal emissivity values and other well-known materials characterization methods such as Fourier Transform Infrared (FTIR), X-ray diffraction (XRD) and Modulated Differential Scanning Calorimetry (MDSC) whichconclusively evidenced the appropriate assimilationof plasters and stuccosapplied inheritage conservation.
\end{abstract}

Keywords: thermal imaging, non destructive testing, materials characterization, heritage conservation

\section{Introduction}

According to the widely accepted Principles of the Conservation of Historic Buildings (British Standards Institution, 1998) which acknowledged the respect and conservation of the historic buildings as a priority, and in cases where a new-fangled material is introduced on behalf of forthcoming restoration. It must be compatible with the original materials color and appearance, in addition to physical, chemical and mechanical characteristics are required to be similar, in order to avoid incompatibility among them.

The use of TIRI is an important technique for inspecting and performing non-destructive testing of construction elements, detecting where and how thermal energy is dispersing from a surface (Avdelidis \& Moropoulou, 2004). Thermal Imaging applied is a non-destructive and non-invasive technique (Candoré, Bodnar, Detalle, \& Grosse, 2010). The collected information is able to be used as part of procedures to identify heterogeneous character of materials and detect former construction interventions (Carosena, Carlomagno, \& Giorleo, 2004). TIRI or Infrared thermography is recognized as a nondestructive testing (NDT) by the ACI committee 228 (ACI Committee 228, 1998, reapproved 2004) in section 2.7, being used in concrete construction for evaluation of the state of older concrete for rehabilitation purposes and quality assurance of concrete repairs. The use in several types of concrete structures such as bridge decks, highway pavement, parking garages and pipelines can be found in literature (Holt \& Manning, 1978; Weil, 1989; 1991). In the same manner, the use of infrared thermography in concrete bridge decks is described in ASTM D4788 (ASTM International, 2007). The typical constructions of historical patrimonies are made of a variety of layered materials. Due to the thermal emission properties, the inside stratum can have consequences on the temperature distribution on the outer surface. It depends on the thickness and thermal properties of the first layer, as well as the thermal capacity of the layers inside. Dense and bulk materials can accumulate heat for a long time which can be visible on the surface, even if it originates from the inside.

There is several research work published on restoration of plasters and stuccos (Toniolo, Paradisi, Goidanich, \& Pennati, 2011; Quagliarini, Lenci, \& Seri, 2012; Abrams, Parhamovich, Butcher, \& McCord, 2012; Riquelme, 
Alvarado-Ortega, Cuevas-García, Ruvalcaba-Sil, \& Linares-López, 2012; Arizzi, Viles, \& Cultrone, 2012). Nevertheless, in the fields of restoration and preservation of World Patrimony, it is relevant the continuos actualization on NDT techniques, such as thermal infrared imaging. Thermal IR cameras detect the energy emitted by a material and deliver a thermal imaging. Truthful emissivity values could provide important information concerning to the interpretation of thermal images as a NDT, validating its correlation with various well known characterization techniques typically applied to building diagnostics for restoration (Rosina et al., 2004).

The aim of this work is figure out all the nature and interrelationship into the relevance of NDT thermal infrared imaging, evaluating carefully as a way of reference to the heritage conservation.

\section{Material Studied}

Three different types of plaster-stucco samples were analyzed in this work. The so called "Original Materials" $(\mathrm{OM})$ were samples obtained from location in the temple where no previous restoration interventions have been carried out. The samples labeled "Restorative Materials" (RM) were new materials used in the building in a restorative process. These materials were applied without a preliminary study of the original materials. The last type of samples was labeled "Formulated Materials" (FM), these samples were new materials used for a restoration process, but they were chemically formulated according to the characterization of the original materials. The samples from sites where one have been done and a total number of eight samples of plaster-stucco from nine different locations of the San Juan Bautista Parish Church were obtained. Samples from SJR1 to SJR7 obtained from the Morelos St. wall facade while samples MC1 and MC2 from Claustro St. wall facade.

\section{Area Description}

The San Juan Bautista's Parish church islocated at the Independence Square, downtown of San Juan del Río, 67 $\mathrm{km}$ from Queretaro City. The construction background dates from 1689 whenthe clergy and the local residents requested the Parish buildingpermission to the Viceroy Don Gaspar de la Cerda Sandoval Silva. In earlier times, the indigenous natives received catholic doctrine and attended mass commonly in a chapel roofed with tejamanil (from nahuatl tlaxamanilli), meaning wood shingles roof, where the Spaniard parish church was finally built. The structure is a neoclassicalconstruction withstylish and spacious lines by distinguished architecture (Instituto Nacional de Antropología e Historia, 2003). Nowadays in this site is adored the Virgin of Guadalupe which is the most iconic belief tradition in México. The former construction materials used were stone basement alikesome of the walls, and adobe bricks and stones widely used for walls and arched roofs of masonry forming domed chambers, sheltered with stuccos used as interior and exterior finishes, applied in thin layers where the last one was colored. The effects of timein this heritage structurefrom the $18^{\text {th }}$ century can particularly be seenat the rear, on the external wall of the Parish House located at Hidalgo Street, as shown in Figure 1.

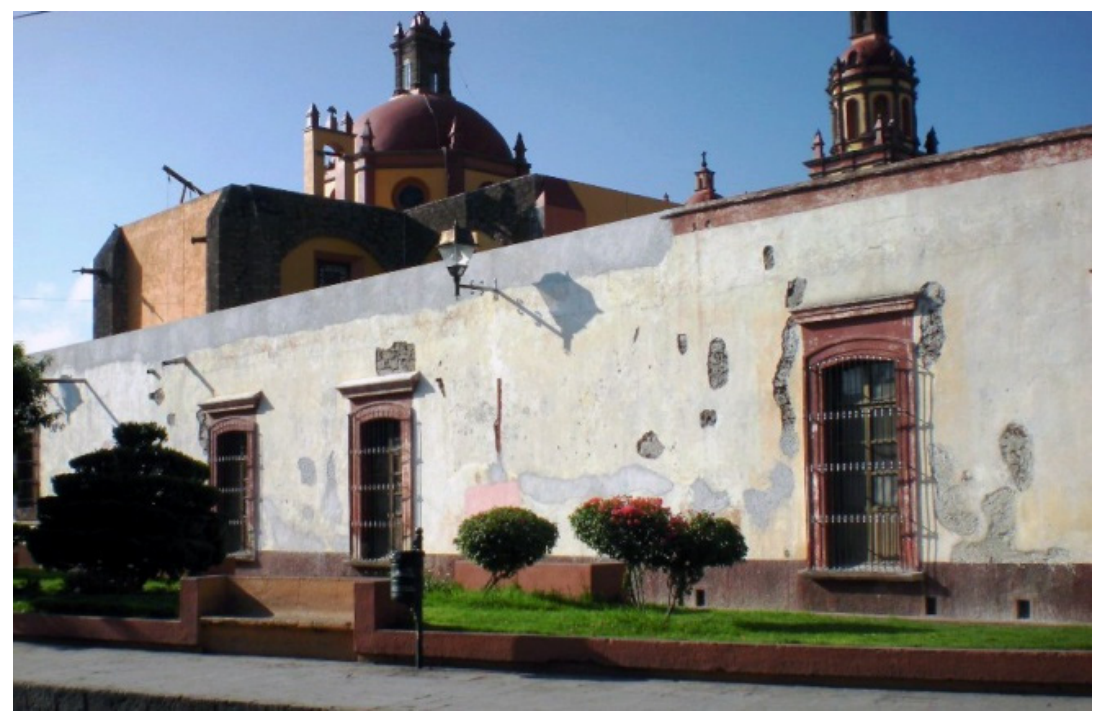

Figure 1. The wall shows damaged areas where plaster sections were missing 
The examination of very old plasters and stuccos is a key aspect of heritage conservation: the mixture of the materials has wide-ranging used throughout the historical period, local knowledge and their specific purpose in the construction (Moropoulou, 2000; Baglioni, Giorgi, \& Dei, 2009; Arndt, 2010). Ancient plasters and stuccos compounds consist of hydraulic or aerial lime and aggregates passive or active, like pozzolans which may react with lime (Galván-Ruiz, Hernández, Baños, Noriega, \& Rodríguez, 2009; Villaseñor \& Graham, 2010; Vejmelková, Keppert, Rovnaníková, Keršner, \& Černý, 2012). Considering the most important thoughtfulness of preservation and restoration processes wherein the alteration of historic sites has to be avoided or at least minimized, the rapid growth and permanent up to day of non-destructive techniques, improve the knowledge in the field of restoration of World Heritage (Hum-Hartley, 1978; Baglioni \& Giorgi, 2006). That is the case of lime-based plasters and stuccos which frequently are restored by using cementor in the worst of the cases, synthetic products such as polymers and epoxy resins. Practice has shown that efforts providing rendering with ordinary Portland cement will not allow water infiltration and regularly fail due to its inelasticity and propensity to fissure (Holmes \& Wingate, 2006).

\section{Materials and Methods}

There were four different testing techniques looking for complementary information that would relate chemical information of the materials and their thermal infraredimaging behavior.

\subsection{Thermal Infrared Imaging (TIRI)}

TIRI was done by a FLIR T400 infrared camera (USA) at ambient temperature (about $18^{\circ} \mathrm{C}$ ), $320 \times 240 \mathrm{IR}$ resolution of 76,800 pixels. In camera emissivity tables, 5 temperature spots $\&$ delta $T$ functionality. Field of view $/ \mathrm{min}$ focus distance $25^{\circ} \times 19^{\circ} / 0.4 \mathrm{~m}\left(1.31 \mathrm{ft}\right.$.). Thermal sensitivity (NETD) $0.05^{\circ} \mathrm{C} @+30^{\circ}\left(+86^{\circ} \mathrm{F}\right) / 50 \mathrm{mK}$. Detector type Focal Plane Array (FPA), uncooled microbolometer. IR resolution 320 x 240.Spectral range 7.5 to $13 \mu \mathrm{m}$. Digital zoom and pan/focus 1-8X continuous/auto \& manual focus IFOV (with $25^{\circ}$ lens) 1.36 $\mathrm{mRad}$.Object temperature ranges $-20^{\circ} \mathrm{C}$ to $+120^{\circ} \mathrm{C}, 0^{\circ} \mathrm{C}$ to $350^{\circ} \mathrm{C}$. Accuracy $\pm 2^{\circ} \mathrm{C}$ or $\pm 2 \%$ of reading. Emissivity is sensitive to several factors as temperature, emission angle, wavelength, the topology of the emitting object surface and color. Consequently, the acquisition of the thermal images were performed at the same period in different wall sites, some of them where restoration processes were made using "Restorative Materials" and others sites where "Formulated Materials" were used. All images were obtained in the same temperature, humidity and weather conditions; moreover, all the wall sites observed had similar topology and color. The main variable analyzed in this study was the emission produce by the different chemical composition between Restorative and Formulated materials.

\subsection{X-Ray Diffraction (XRD)}

$\mathrm{X}$-Ray diffraction analyses were carried out in order to identify the crystals mineral component in the original plasters and stuccos. The X-ray diffraction patterns of the plaster powders were obtained using a diffractometer Siemens D5000 (Germany), operated at $35 \mathrm{kV}$ and a $15 \mathrm{~A}$ current, using the $\mathrm{Cu} \mathrm{K} \alpha$ radiation wavelength of $1.5406 \AA$. The measurements were made at room temperature, from $10^{\circ}$ to $70^{\circ}$ on $2 \theta$ with a step size of $0.05^{\circ}$. Preparation of the samples was done by grinding the retrieved materials and to obtain fine powders by means of an agate mortar. These were then passed through a number 60 sieve $(0.25 \mathrm{~mm})$.

\subsection{Fourier Transform Infrared (FTIR)}

Infrared spectroscopy was used to identify mineral and organic components in the original stuccos and plasters. Some components in the original materials could be amorphous. Thus, those components are not possible to be analyzed by XRD. Organic compounds may havebeen used in the formulation of the original stuccos and plasters and FTIR analysis are useful to identify their presence. Samples were milled to obtain fine powders which were mixed with $\mathrm{KBr}$ powder. The FTIR analyses were carried out by means of a spectrophotometer Bruker Vector 33 using diffuse reflectance technique with a resolution of $4 \mathrm{~cm}^{-1}$.

\subsection{Modulated Differential Scanning Calorimetry (MDSC)}

This technique was used to determine the thermal behavior of stuccos and plasters and their possible kinetic and structural changes produced by the temperature variation. The instrument used was a Temperature Modulated Scanning Calorimeter TA Instruments 2920 series, with a constant disc as heat transfer item. Baseline calibration was made with an empty aluminium pan. Cell constant and temperature calibration were performed using mercury and indium. The samples were milled; then, $15 \mathrm{mg}$ of the powder was placed inside a calorimeter cell. The temperature range in the analysis was from room temperature to $500{ }^{\circ} \mathrm{C}$. The heating rate was $5^{\circ} \mathrm{C} / \mathrm{min}$ and a modulation of $+/-0.796^{\circ} \mathrm{C}$ every $60 \mathrm{~s}$. Calorimeter cell was purged with a constant nitrogen flow of $80 \mathrm{ml} / \mathrm{min}$. 
An empty aluminium pan was used as reference. When the above instrument calibration was over, the experiments were carried outstraight away.

\subsection{Reproduction of the Original Materials and Placement}

One of the main problems in the case of restoration is to develop materials with similar characteristics of the original ones (Figures 2 and 3). A practical procedure to achieve similar grain-size distribution like the former was developed. Plaster wascollected from the walls of the building and paint (vinyl paint, fraction of the original lime paint) removed manually; $150 \mathrm{~g}$ of plaster free of paint was milled and stirred for 30 minutes in a $500 \mathrm{ml}$ beaker with $250 \mathrm{ml}$ of distilled water, in order to separate the sand particles, organic particles, and the calcium carbonate fraction. The calcium carbonate particles were then separated by gravity removing the water several times. With this techniqueis possible to obtain a correspondingsample toapproximately the same lime/sand ratio used in the original plaster. The binder-aggregate ratio of plaster samples were in the range of 1:2-1:3. Particle sizes that are greater than $1180 \mu \mathrm{m}$ composed the largest sizes of the total aggregates, and aggregates were composed of Quartz, Albite and Anorthite.

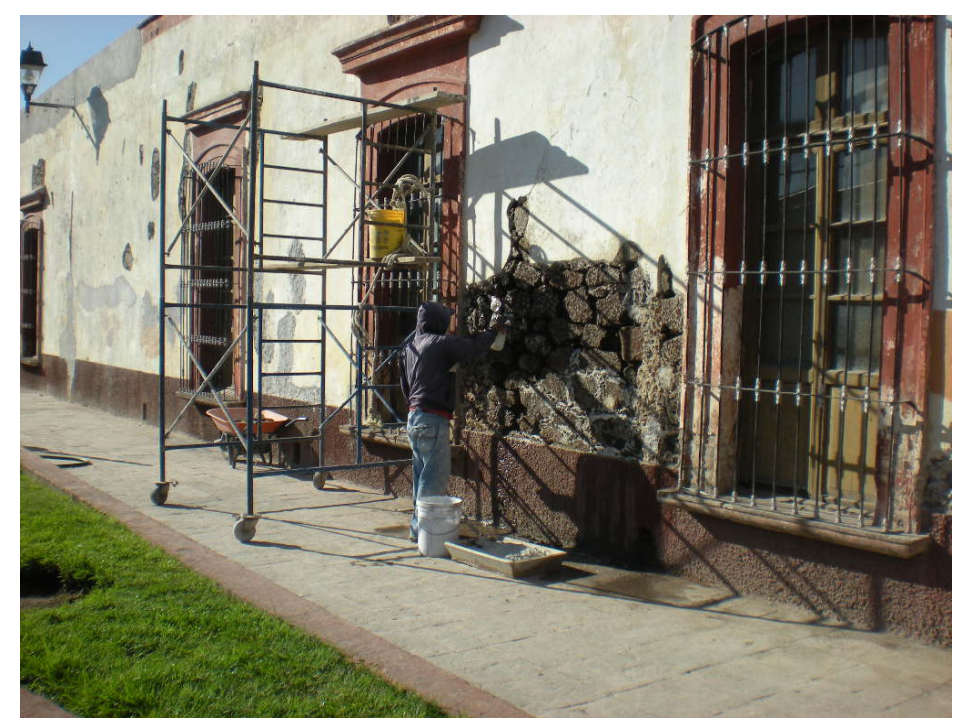

Figure 2. Application of the lime putty-sand-pozzolan mixture proposed in the restoration process

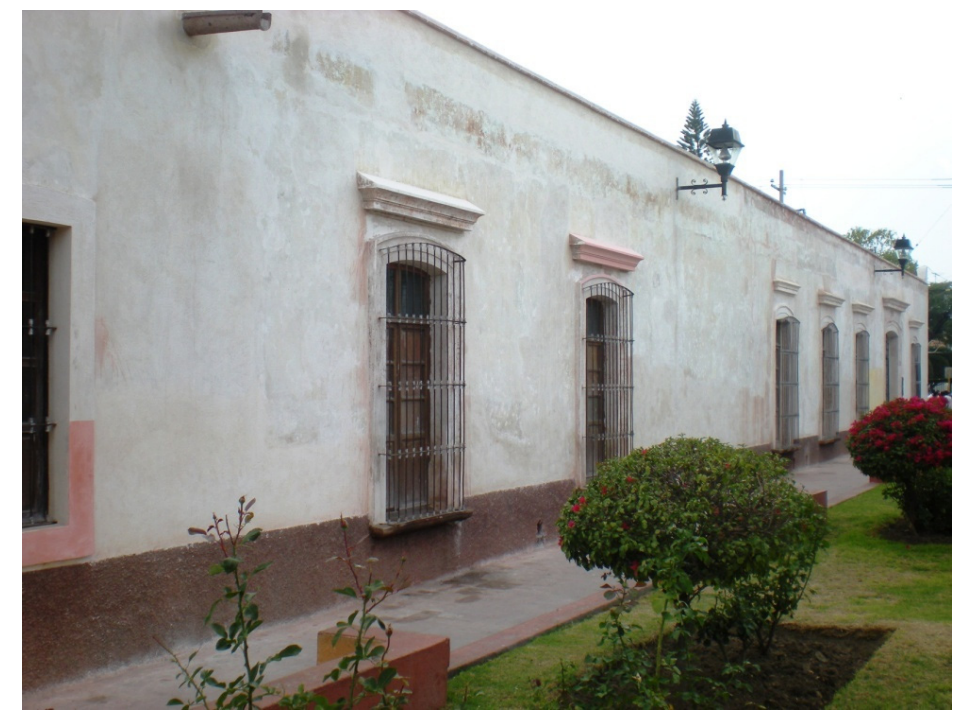

Figure 3. View of restoration process. Facade after the proposed plaster application on damaged areas, before the final colored stucco layer 


\section{Results and Discussion}

\subsection{FTIR}

The diffractograms obtained from the analyses of the all materials are shown in Figure 4. Here it is possible to observebroad signals about 3600 which correspond to water absorbed in the stucco samples. The signals at 3706 , $3640, \mathrm{~cm}^{-1}$ correspond to $(\mathrm{OH})$ groups in the $\mathrm{Ca}(\mathrm{OH})_{2}$ (Portlandite). These signals were recorded only in the samples RM1 and RM2 which are samples from regions in the building where previous restoration interventions were made. Essentially, the presence of Portlandite was evidence of how recent those materials are. The Portlandite reacts with the $\mathrm{CO}_{2}$ content in the environment, changing to calcite $\left(\mathrm{CaCO}_{3}\right)$ (Galván-Ruiz et al., 2009).

The signal at $1795 \mathrm{~cm}^{-1}$ was related to the $\mathrm{C}=\mathrm{O}$ bond, and the bandsat $2515,1450,865,790$ and $705 \mathrm{~cm}^{-1}$ were generated by the $\mathrm{C}-\mathrm{O}$ bond. All those signals were associated to the carbonate group $\left(\mathrm{CO}_{3}\right)$ in the calcite. The signals at 2990 and $2870 \mathrm{~cm}^{-1}$ may be produced by both, the overtones of C-O bond and the presence of organic (aliphatic) compounds (C-H bonds). From the XRD results, the calcite is the main inorganic constituentin the samples and the concentration of this mineral is similar in all samples; thus, it is possible to assume that the variations on the relative intensity for the bands at 2990 and $2870 \mathrm{~cm}^{-1}$ are related mainly to different quantities of organic material in the stuccos and plaster. As a consequence, the OM4 was the sample with the higher concentration of organic materials. In contrast, the sample OM2 showed the lowest amount of organic compounds.In addition, signals at 1180,1040 and $1018 \mathrm{~cm}^{-1}$ were registered and correlated to the quartz, other component detected by XDR as well. In addition, the Albite was also detected by XRD, the (Si-O) groups in this mineral are similar to those in the quartz and the (Si-O-Al) groups produce signals about $1100 \mathrm{~cm}^{-1}$. These signals were overlapped with the signals corresponding to quartz in the stucco samples; consequently, it was difficult to make a differentiation of these two mineral by FTIR. The broad bands from 920 through $1270 \mathrm{~cm}^{-1}$ appeared wider due not only by the overlapping mentioned above, but also by the chemical interaction with water.

The samples RM1 and RM2 do not contain Albite according to XRD and thus, their signals corresponding to quartz were clearer than those recorded for the rest of the samples; essentially, the profile of the signals from 920 through $1270 \mathrm{~cm}^{-1}$ for these samples were different from the rest as a consequence of the lack of Albite. And this is the main difference in the spectra of RM1 and RM2 samples compared to the rest of the samples. On the other hand, the samples FM1 and FM2 showed similar spectra to those observed for the OM samples. The last is evidence of the chemical similarity of these samples and the original materials used in the building.

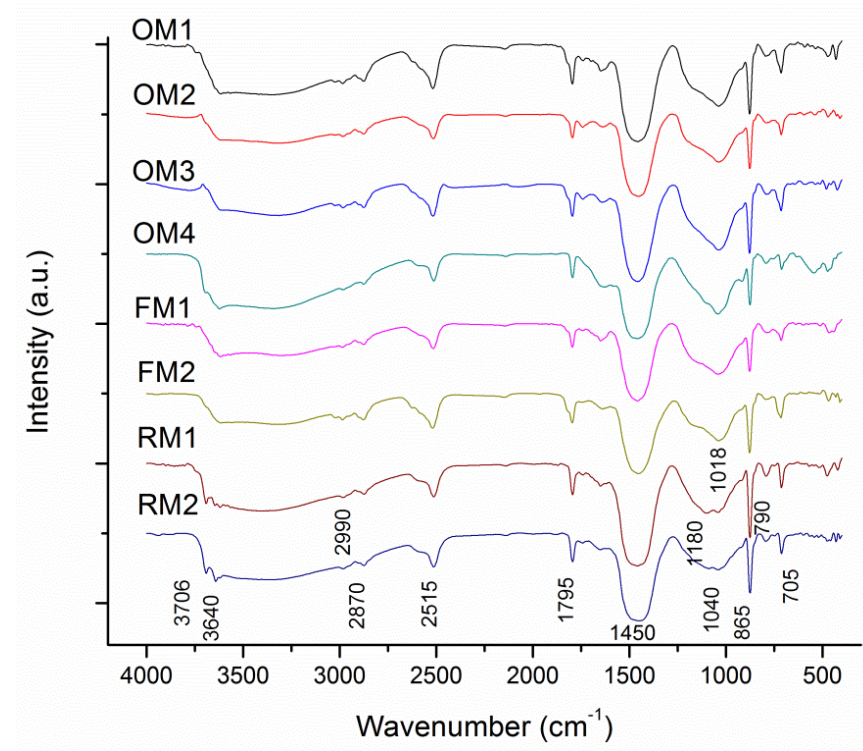

Figure 4. FTIR diffractograms of the different render-stucco samples. The main signals were tagged for their identification 


\subsection{XRD}

The resultsobtained by means of XRD were consistent to those found in FTIR analyses and confirm the presence of most of the minerals in the sample composition. All samples were highly crystalline as it is shown in Figure 5. In all samples calcite (PDF 47-1743) was found as the main mineral constituent. Moreover, different quantities of quartz (PDF46-1045) were determined in the stucco samples. A small amount of Albite (PDF 09-0466) was also determined in all the samples, except for RM1 and RM2. Most of the samples have similar chemical composition; the main variation is the concentration of quartz and Albite from sample to sample.

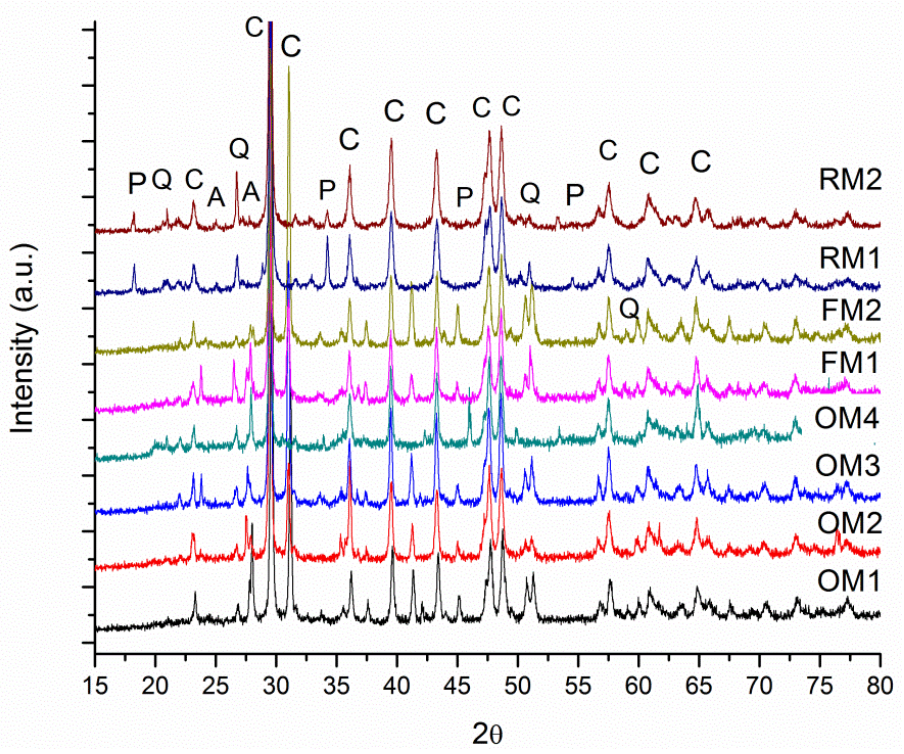

Figure 5. Diffractograms of the different plaster-stucco samples. OM1 results at the bottom and RM2 at the top.

Most of the signals were tagged indicating the chemical composition

In addition, a small concentration of Portlandite (PDF 04-0733) was determined only in the RM1 and RM2 samples. The finding of this mineral confirms the argument depicted above about the recent application of the materials contented in these samples. The presence of Portlandite and the lack of Albite is thatmade different these samples from the rest, and these differences were relevant in the IR images. Differences in chemical composition produces different color contrast in the IR images. Once again, it is remarkable the similarity between the diffractograms of FM1 and FM2samples to those obtained from the samples of the original materials.

\subsection{MDSC}

The modulated calorimetry also showed quite relevant results. Figure 6 shows the non-reversible heat flow as a function of the temperature of all samples. In this type of analysis, depending of time and temperature, transitions and kinetic changes were developed in all the samples. It is possible to see in the Figure 6 that all the original materialsamples had a similar thermal profile, except OM4. The samples presented a broad exothermal signal about $110^{\circ} \mathrm{C}$ which corresponds to both, the evaporation of water and the thermal degradation of the organic compounds. This degradation was the most important kinetic change in the samples. The enthalpy values recorded forthese signals weresimilar for most of the original material samples, but it was rather different for OM4. The highest enthalpy valuewas determined for OM4 $(157 \mathrm{~J} / \mathrm{g})$. This enthalpy value was almost 2.66 times bigger than the average value for the rest of the OM samples $(59.9 \mathrm{~J} / \mathrm{g})$ and the smallest onewas for the case of OM2 $(50 \mathrm{~J} / \mathrm{g})$. Moreover, the OM4 sample also showed an overlapped signal about $145^{\circ} \mathrm{C}$ which was generated by the degradation of a high concentration of organic material.

The last statements confirm the findings in the former analytical techniques. Sample OM4 has the highest organic compound content and OM2 the lowest concentration.

The RM1 and RM2 showed thermal profiles somewhat different from the OM samples. They had a broad signal at $115{ }^{\circ} \mathrm{C}$ for RM2 and $130{ }^{\circ} \mathrm{C}$ for RM1. The profile of this signal was similar to that recorded for OM4, but the enthalpy values were quite different, 85.5 and $76.9 \mathrm{~J} / \mathrm{g}$ for RM1 and RM2 respectively. It is possible that the 
presence of $\mathrm{Ca}(\mathrm{OH})_{2}$ produced a lot of hydrogen bonds in its interaction with water. This different thermal behavior observed in RM1 and RM2 is a consequence of their different chemical composition which ratifies the matchless of these add-mixtures compared with the originals. The later does not agree with the Principles of the Conservation of Historic Buildings.

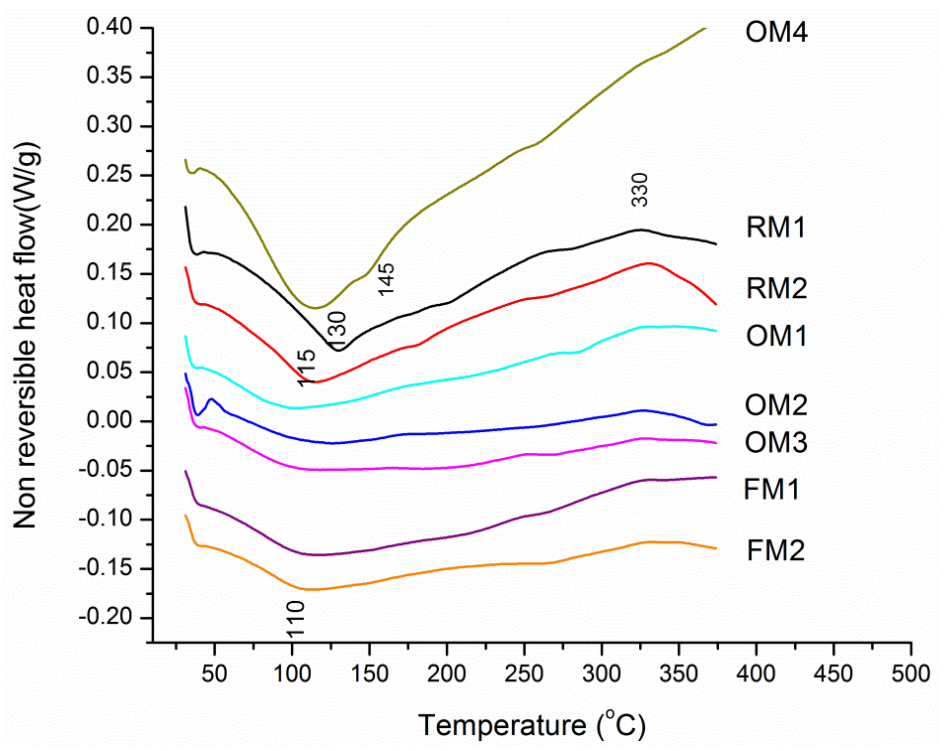

Figure 6. Non-reversible heat flow as a function of time for all samples

In addition, the variation of the heat capacity as a function of temperature was analyzed for all samples. Any change in the heat capacity develops thermal instability in the material of the samples. According to Figure 7, the samples that underwent the highest change in heat capacity were OM4 $\left(0.2395 \mathrm{~J} / \mathrm{g}{ }^{\circ} \mathrm{C}\right)$ and $\mathrm{RM} 1\left(0.1983 \mathrm{~J} / \mathrm{g}{ }^{\circ} \mathrm{C}\right)$. In the case of RM1, the heat capacity variations were due to the water contained in the sample and the thermal behavior of the $\mathrm{Ca}(\mathrm{OH})_{2}$. In OM4, the heat capacity variations were related to the organic compound content. In contrast, the sample with the lowest variation in heat capacity was OM2 $\left(0.04535 \mathrm{~J} / \mathrm{g}{ }^{\circ} \mathrm{C}\right)$ which indicates that this sample is also the most thermallystable because it was formed by temperature inert materials. This stability can also be related with the low organic material concentration in the sample.

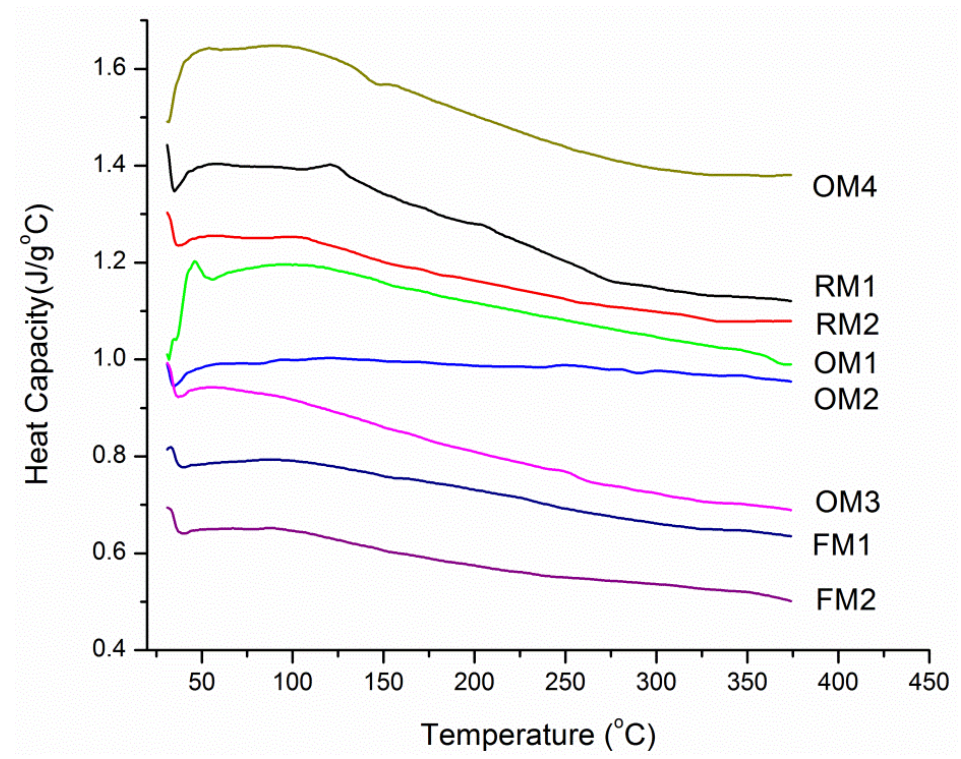

Figure 7. Heat capacity curves of all samples 
The thermal behavior of FM1 and FM2 samples was quite similar to that showed by the original materials; then, it is possible to establish that the formulated materials have similar chemical and physical properties than those observed in the original materials.

\subsection{TIRI}

The chemical composition andsurface roughness or appearances are also variables that can influence on emissivity. The IR color patterns observed in the image of the Figure 8a shows dissimilar emissivity from the constituentmaterials on a portion of the wallsurface. When this image was compared to the conventional image portrayed on Figure $8 \mathrm{~b}$ without using TIRI, the differences are remarkable. The Figure 8a shows a passive approach with the intention of compare the natural thermal gradient on the surface. To optimize the resolution on the thermal variation, the measurements were done perpendicularly to the wall surface.

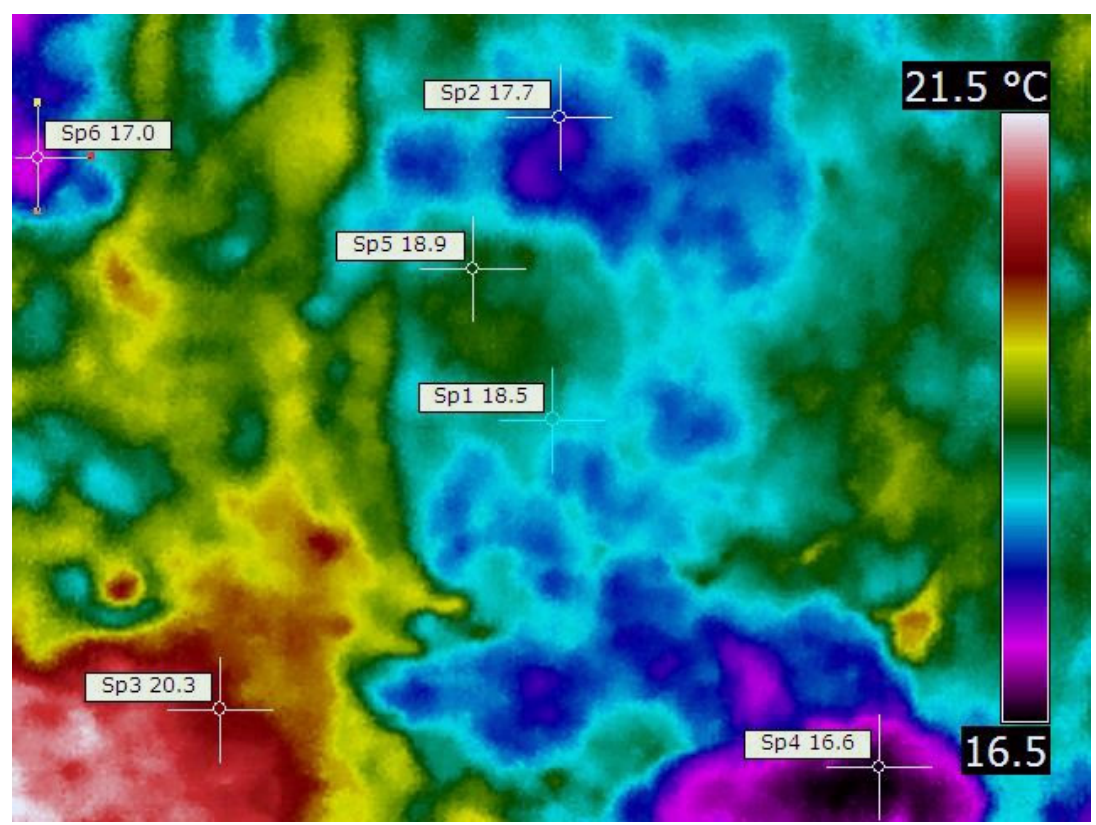

Figure 8a. Thermal IR image from a wall at Parish House, Morelos Street, San Juan Bautista Parish

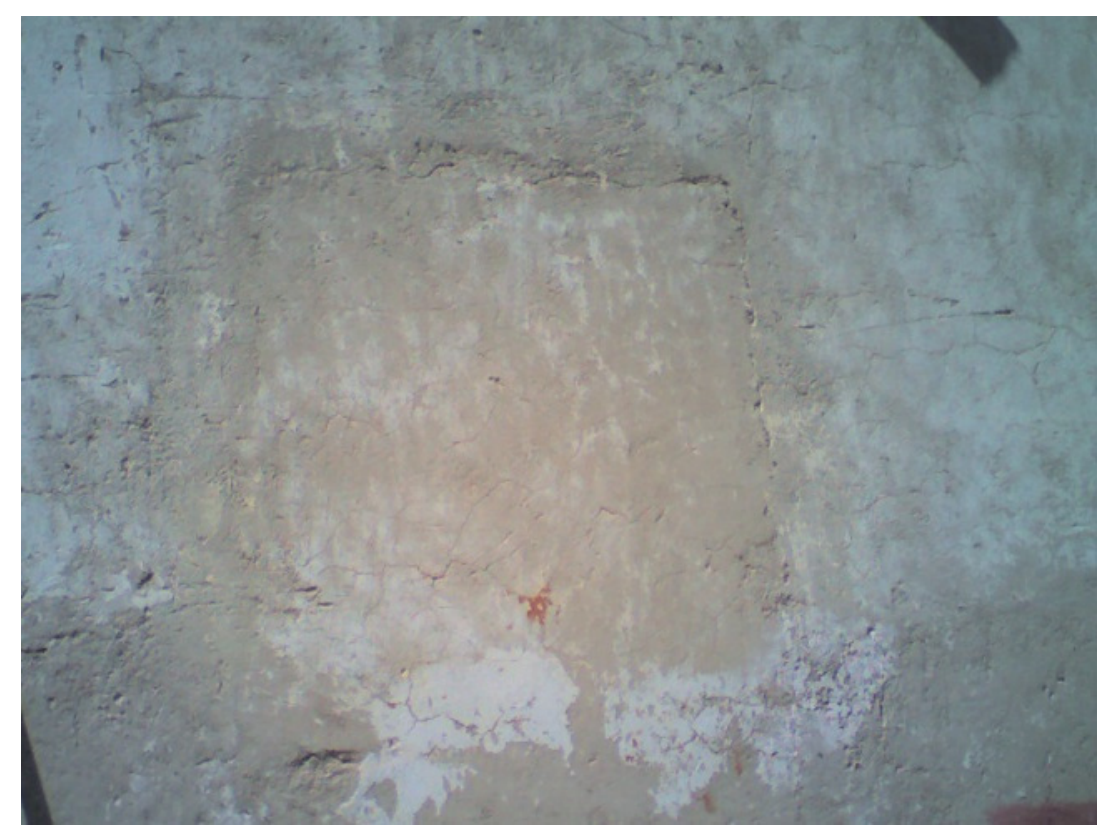

Figure 8 b. Digital image was obtained with the same IR camera position matching with Figure 8 a. There is strong evidence of former inappropriate intervention on this area 
This image showed temperature varied in the wall surface from 16.6 through $20.3{ }^{\circ} \mathrm{C}$. This temperature variation was produced mainly by the differences in chemical composition between the original material constituents in the wall and the applied restorative materials.

Keen-sighted emissivity is a measure of a material's radiating efficiency; therefore, an emissivity of 0.96 as it was observed, suggests that the material is close to $100 \%$ efficient at radiating energy.

Figure 9a shows a thermal photograph after 6 months of the application of the plaster prepared using the formulated material which contains lime, sand and pozzolan in an analogous composition than that in the original. The image also showed that the temperature variation on the wall was from $12.5^{\circ} \mathrm{C}$ to $12.9^{\circ} \mathrm{C}$.

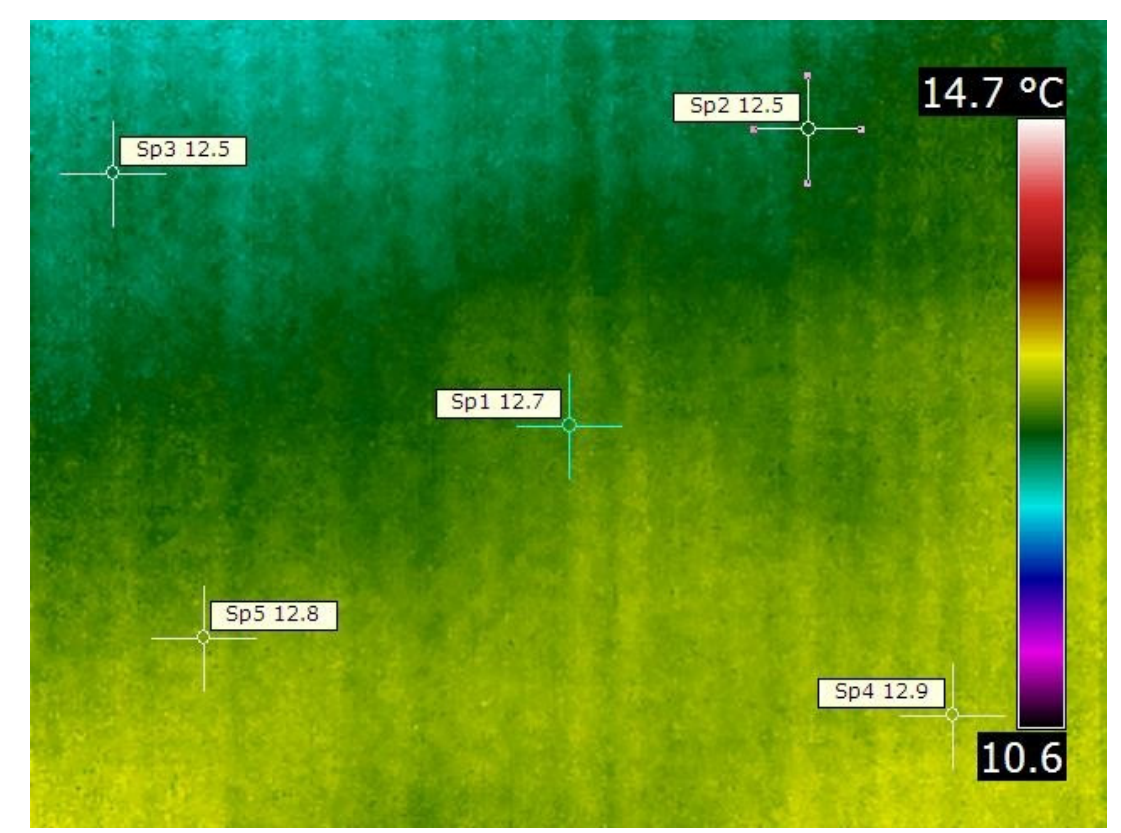

(a)

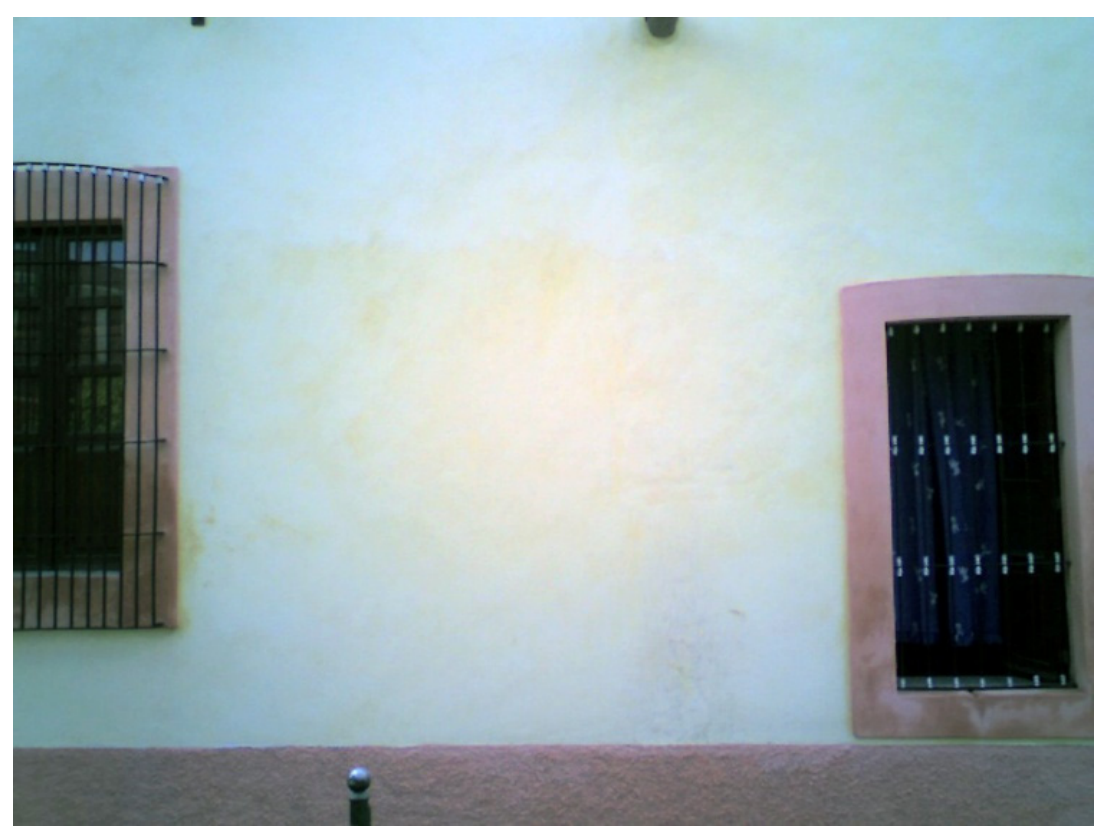

(b)

Figures 9. (a) and (b) were taken from similar position in the location of interest, linking thermal and digital images 
The emissivity was 0.96 , with a reflected temperature $20^{\circ} \mathrm{C}$, an atmospheric temperature $16{ }^{\circ} \mathrm{C}$, and relative humidity of 0.4 . The distance was $4 \mathrm{~m}$. Figure $9 \mathrm{~b}$ shows the same spot without the TIRI effect.

Additionally, in Figures 10a and 10b, the window frame was a good reference to make easier thecorrelation between the digital image and the appeared thermal image. It is relatively easy to identify the window edge in the thermal image by its different energy emission compared to that from the restored area. Once again, the thermal image shows a small temperature variation on the wall surface from $27.4{ }^{\circ} \mathrm{C}$ to $27.9{ }^{\circ} \mathrm{C}$, and this is evidence of the similar chemical composition of the restored sites and the original ones. All these images were obtained underidentical condition, position and using the same camera in thermal and digital modes respectively. Note that the scales show a discrepancy. Nevertheless, the area could be clearly recognized from side to side beside the window edge.

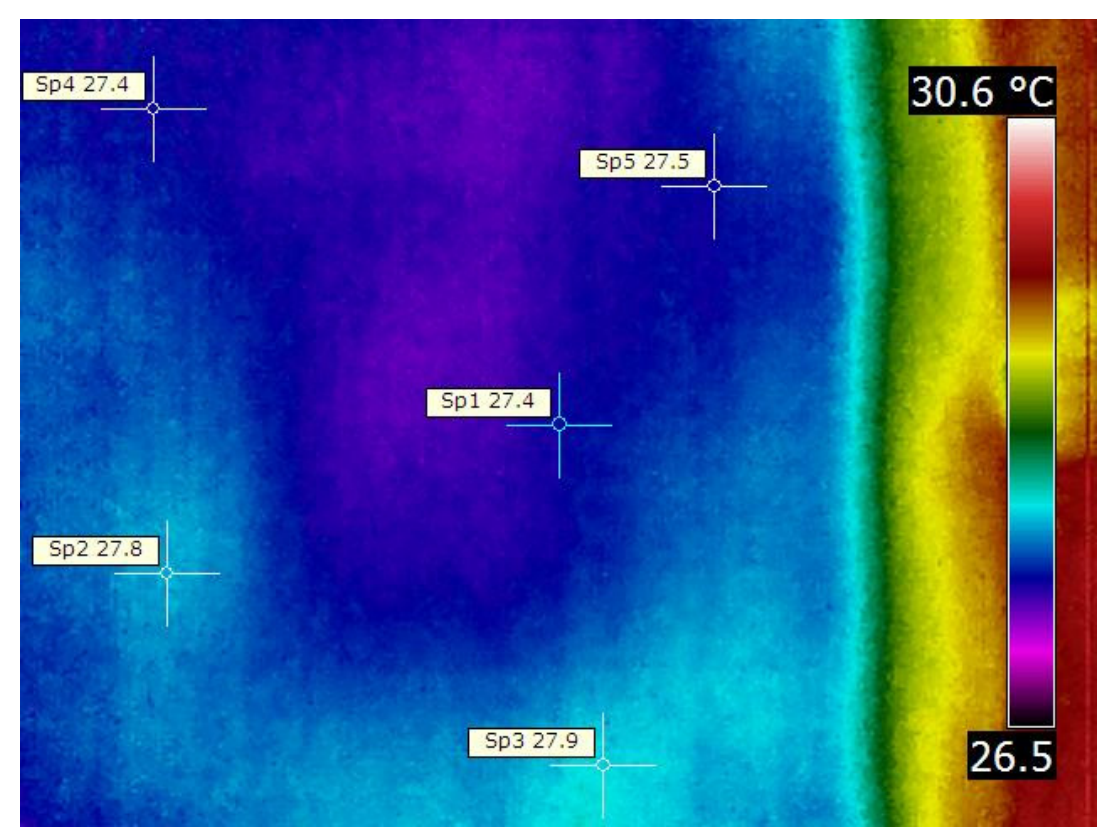

(a)

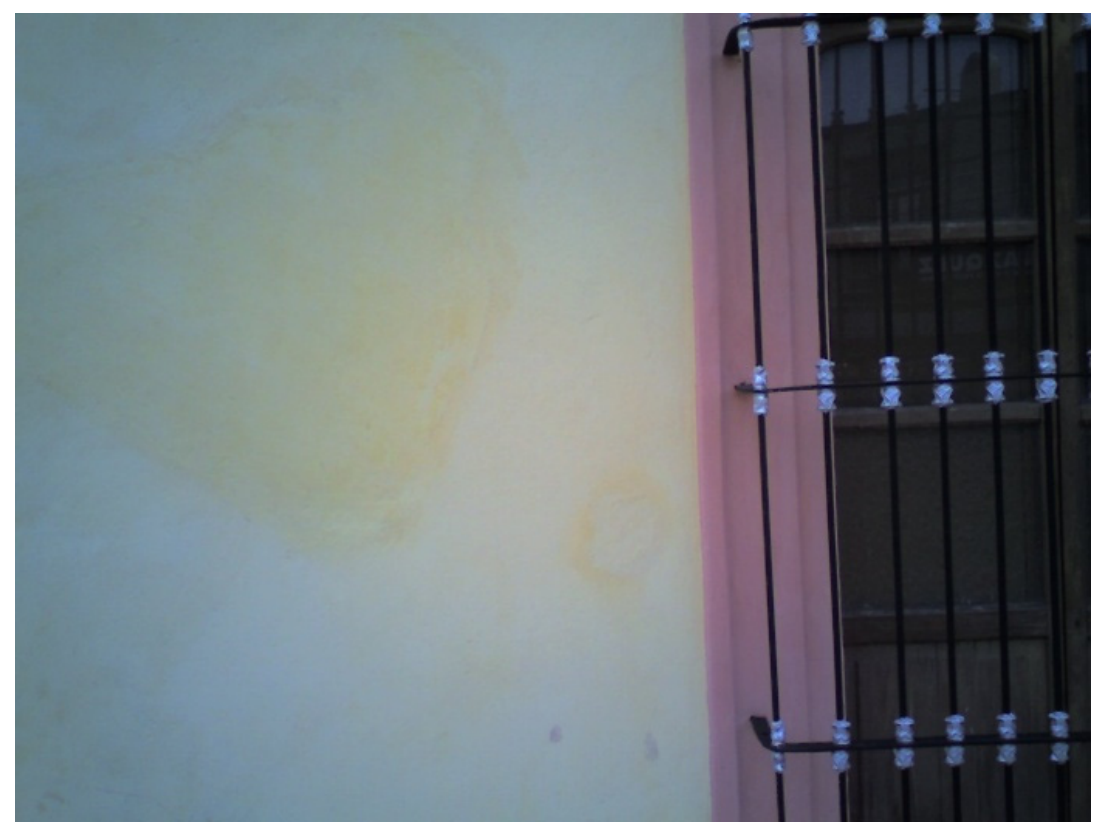

(b)

Figures 10. Matched thermal and digital images of similar restored zone after six months of the proposed formulated plaster-stucco application 


\section{Conclusions}

The chemical composition of the original materials was undoubtedly identified and their mineral constituents were recognized. Therefore, new formulated materials compatible with the original ones were obtained and applied in the restoration process.

Despite the close emissivity values between lime-plaster and cement composites, TIRI images weresuitable to distinguish the particular areas where former restoration process have been carried out in an apparently homogeneous wall surface. Moreover, TIRI showed plane thermal images in those places where formulated materials were used. The differences in these thermal images could be directly related to the differences in chemical composition according to the results of the characterization analysesin original and restoration formulated plasters and stuccos.

The significance of this work provides strong evidence which exhibit the proficiency of thermal infrared imaging as a NDT technique, to differentiate concerning original plasters and stuccos and far ahead interventions with mismatched materials.

\section{Acknowledgements}

Authors would like to express their gratitude to Samuel Kolosovasand René Plaza for their technical assistance. The research was financially supported within the CONACYT project 104860, "Caracterización mecánica y físico química de materiales polifásicos basados en cal, utilizados en construcciones prehispánicas y coloniales".

\section{References}

Abrams, E., Parhamovich, J., Butcher, J., \& McCord, B. (2012). Chemical composition of architectural plaster at the Classic Maya kingdom of Piedras Negras, Guatemala. Journal of Archaeological Science, 39(5), 1648-1654. http://dx.doi.org/10.1016/j.jas.2012.01.002

ACI Committee 228. (1998, reapproved 2004). Nondestructive test methods for evaluation of concrete structures. American Concrete Institute.

Arizzi, A., Viles, H., \& Cultrone, G. (2012). Experimental testing of the durability of lime-based mortars used for rendering historic buildings. Construction and Building Materials, 28(1), 807-818. http://dx.doi.org/10.1016/j.conbuildmat.2011.10.059

Arndt, R. (2010). Square pulse thermography in frequency domain as adaptation of pulsed phase thermography for qualitative and quantitative applications in cultural heritage and civil engineering. Infrared Physics \& Technology, 53(4), 246-253. http://dx.doi.org/10.1016/j.infrared.2010.03.002

ASTM International. (2007). Annual Book of Standards, ASTM D4788 - 03. Standard Test Method for Detecting Delaminations in Bridge Decks Using Infrared Thermography. ASTM.

Avdelidis, N., \& Moropoulou, A. (2004). Applications of infrared thermography for the investigation of historic structures. Journal of Cultural Heritage, 5(1), 119-127. http://dx.doi.org/10.1016/j.culher.2003.07.002

Baglioni, P., \& Giorgi, R. (2006). Soft and hard nanomaterials for restoration and conservation of cultural heritage. Soft Matter, 2, 293-303. http://dx.doi.org/10.1039/b516442g

Baglioni, P., Giorgi, R., \& Dei, L. (2009). Soft condensed matter for the conservation of cultural heritage. Comptes Rendus Chimie, 12(1-2), 61-69. http://dx.doi.org/10.1016/j.crci.2008.05.017

British Standards Institution. (1998). Guide to the principles of the conservation of historic buildings. London: BSI.

Candoré, J., Bodnar, J., Detalle, V., \& Grosse, P. (2010). Non destructive testing in situ, of works of art by stimulated infra-red thermography. Journal of Physics: Conference Series, 214, 1.

Carosena, C., Carlomagno, G., \& Giorleo, L. (2004). The use of infrared thermography for materials characterization. Journal of Materials Procesing Technology, 155-156. http://dx.doi.org/10.1016/j.jmatprotec.2004.04.268

Galván-Ruiz, M., Hernández, J., Baños, L., Noriega, J., \& Rodríguez, M. (2009). Characterization of Calcium Carbonate, Calcium Oxide, and Calcium Hydroxide as Starting Point to the Improvement of Lime for Their Use in Construction. Journal of Materials in Civil Engineering, 694-698. http://dx.doi.org/10.1061/(ASCE)0899-1561(2009)21:11(694) 
Galván-Ruiz, M., Velázquez-Castillo, R., Pérez-Lara, M., Arjona, J., Baños, L., \& Rodríguez-García, M. (2009). Chemical and physical characterization of stuccos from a Mexican Colonial building: El Museo del Calendario of Querétaro. Archaeometry, 51(5), 701-714.

Holmes, S., \& Wingate, M. (2006). Building with lime. UK: ITDG Publishing.

Holt, F., \& Manning, D. (1978). Infrared Thermography for detection of delaminations in concrete bridge decks. Proceedings Forth Biennial Infrared Information Exchange, pp. 1-71.

Hum-Hartley, S. (1978). Nondestructive Testing for Heritage Structures. Bulletin of the Association for Preservation Technology, 10(3), 4-20. http://dx.doi.org/10.2307/1493664

Instituto Nacional de Antropología e Historia. (2003). Catálogo Nacional de Monumentos Históricos Inmuebles.Querétaro: CONACULTA.

Moropoulou, A. A. (2000). Compatibility assessment of building materials using Infrared Thermography. 15th World Conference on Nondestructive Testing. Roma: ICNDT.

Quagliarini, E., Lenci, S., \& Seri, E. (2012). On the damage of frescoes and stuccoes on the lower surface of historical flat suspended light vaults. Journal of Cultural Heritage, 13(3), 293-303. http://dx.doi.org/10.1016/j.culher.2011.11.008

Riquelme, F., Alvarado-Ortega, J., Cuevas-García, M., Ruvalcaba-Sil, J., \& Linares-López, C. (2012). Calcareous fossil inclusions and rock-source of Maya lime plaster from the Temple of the Inscriptions, Palenque, Mexico. Journal of Archaeological Science, 39(3), 624-639. http://dx.doi.org/10.1016/j.jas.2011.10.022

Rosina, E., Avdelidis, N., Moropoulou, A., Della Torre, S., Pracchi, V., \& Suardi, G. (2004). IRT Monitoring in Planned Preservation of Built Cultural Heritage. World Conference on NDT. Montreal: 16th WCNDT.

Toniolo, L., Paradisi, A., Goidanich, S., \& Pennati, G. (2011). Mechanical behaviour of lime based mortars after surface consolidation. Construction and Building Materials, 25(4), 1553-1559. http://dx.doi.org/10.1016/j.conbuildmat.2010.08.010

Vejmelková, E., Keppert, M., Rovnaníková, P., Keršner, Z., \& Černý, R. (2012). Application of burnt clay shale as pozzolan addition to lime mortar. Cement and Concrete Composites, 34(4), 486-492. http://dx.doi.org/10.1016/j.cemconcomp.2012.01.001

Villaseñor, I., \& Graham, E. (2010). The use of volcanic materials for the manufacture of pozzolanic plasters in the Maya lowlands: a preliminary report. Journal of Archaeological Science, 37(6), 1339-1347. http://dx.doi.org/10.1016/j.jas.2009.12.038

Weil, G. (1989). Nondestructive remote sensing of subsurface utility distribution pipe problems using infrared thermography. Proceedings Second International Conference on Pipeline Construction Congress.

Weil, G. (1991). Infrared Thermographic Technique. In e. Malhotra and Carino, Handbook on Nondestructive Testing of Concrete, Chapter 13 (pp. 305-316). Boca Raton, Fla.: CRC Press. 